\title{
A Comparison between Online and Offline Health Seeking Information using Social Networks for Patients with Chronic Health Conditions
}

\author{
Dr Andrew Kear ${ }^{1}$ \\ Faculty of Media and Communication \\ Bournemouth University, UK
}

\author{
Simon Talbot ${ }^{2}$ \\ Welspect Healthcare \\ UK
}

\begin{abstract}
The patient is now better connected with other patients just like the consumer is now better connected with other consumers in particular through the growing adoption of social media and online peer to peer communities. These relationships which become collaborative have either positive or indeed negative consequences that may either endorse or have implications for a firm's products [32]. The aim of this research was to gain an understanding of the impact social media has on patient influence on healthcare provision especially in relation to information seeking and clinical product choice. It compares a group of patients who are predominantly online information seekers with a group who are predominantly offline information seekers. Bias will be eliminated by utilising probability sampling techniques in order to be able to perform statistical analysis on the results obtained. This study capitalises on having access to approximately $\mathbf{8 0 0 0}+$ Direct to Patient consumers who are currently receiving devices for the management of their bladder problems. The intention of this research project is to gain an understanding of how two way online interactions have developed between patients with similar chronic medical conditions and how firms can use online social media to improve their relationship with patients. The key research question of this paper is: Have online social media tools affected demand for healthcare intermediation in patients, who experience chronic medical conditions and reflect a need to become better informed. The findings of this pre-Covid research were that, for patient groups that had chronic conditions, there was a positive relationship between time spent in developed peer to peer communities, are more trusting of online information and spend more time online.
\end{abstract}

Keywords-Component; social media; healthcare; peer to peer networks; patient networks; pre-Covid

\section{INTRODUCTION}

The digital revolution through information technology has had an empowering influence on interactions between consumers (the end users) and consumers, and consumers and the marketplace. Social media has allowed instant reach to and sharing of information [14] and Social media penetration world-wide is continuously on the uptrend to move to over 3 billion by 2021 (Statista.com) [34]. Social media interactions offer a medium to be used by patients with informational, emotional, and social support pertaining to their issues [42]. This can offer both valuable information and in some cases misleading information. Consumers, in this case patients, have an increasingly loud voice and identity as online social peer to peer groups form,9 members of those groups or communities interact with each other [29] and social networks have now become a major component of popular culture [4]. Users of member communities are potentially open to influences, especially from other members within these communities. To search for other patients (consumers) knowledge and experiences [1] remains a key driver in this context. Individuals who never meet face to face today develop an identity and presence within member communities spanning across the globe. Facebook allowed patients to follow healthrelated pages. YouTube and Twitter are the next two widely used social media platforms. Patients are also able to participate in disease-specific group discussions [2] In a McKinsey survey (2011) involving 4261 respondents 67\% of Healthcare companies use at least one social technology tool [16]. Now most businesses, social causes, political movements, public figures and governments' attempt to harness the power of social network sites such as Facebook due to the level of exposure and influence it offers [4]. Thus the benefits of adopting social media for the firm are clear and it is proposed that the patient-provider relationship is enhanced across all age groups (Ybarra \& Suman, 2008). One of the key challenges faced by firms, according to a 2012 McKinsey survey, is a lack of quality detailed customer data, for example consumer interests or attitudes [5]. This in turn means that marketing decisions have to be based on known or 'comfortable' data such as internal sales data. This McKinsey survey concluded that less than $20 \%$ of marketing decisions are based on external quantitative and qualitative data such as consumer insights, these insights were described as difficult to obtain due to the fact that they are not readily available to the firm [5].

Information seeking is linked to decision making. Roxane Divol [28], in her article entitled 'Demystifying Social Media' describes the consumer decision journey as consisting of 5 stages: 'Consider, evaluate, purchase, experience then advocate' [28]. This stage process has resemblances with the search, experience, and credence model that has been studied in on line shopping [11]. The author in [28] in her paper argues that it is much easier to interact with the consumer at each of the five decision making stages through social media, compared with a more traditional paid media marketing strategy. This means that a social media marketing strategy brings undoubted benefits such as access to the consumer at each stage of the decision making journey. However social 
marketing is of course not without its risks. Online communities such as blogs and peer to peer user groups can campaign for unproven or untested treatments. One example is a new untested surgical treatment for Multiple Sclerosis being 'advocated' by an online Canadian community group [10]. Today most clinicians take a positive view of the information found through online searches that patients bring to their clinics [36].

According to [38] 'patients are acquiring more power in the health care supply chain and their preferences are influencing manufacturers, physicians and hospitals' [36]. Therefore patients have influence over prescribed products they receive and have power over which products will appear on formularies in future. Online health information has now grown to become one of the most important information sources for people [17]. Pharmaceutical companies meanwhile provide product information that increases request rates [24]. Patients with chronic health conditions carry out regular searching for information relating to new treatments, nutritional advice and alternative therapies. Patients use both online communities and chat rooms. Today the adoption of online health information seeking behaviour is creating a more informed patient. This greater transparency of information does create issues. For instance, the large number of products potentially creates confusion amongst clinicians which in turn leads to examples of products being unnecessarily or inappropriately prescribed. A key tactic amongst newly formed Clinical Commissioning Groups is to develop what is known as a 'formulary', essentially this is a list limiting the prescription of products. These formularies limit the availability of some of these devices, based on criteria such as clinical or cost effectiveness.

Key questions arise as to differences between online and offline health seeking behaviours and their implications for health care provision. If a proven difference exists between online and off-line information seeking behaviours, especially in the context of patients with long term chronic illnesses, then this would have significant implications for the understanding of consumer behaviour. It would either imply that the patient had already 'decided' before they consulted with a clinician or at least would suggest that there are external influences on choice of treatment that the patient receives from their clinician. A further thing to note is that there are many benefits to researching illness and chronic illnesses beyond that of metaphor [33].

The factors influencing peer to peer communities can be grouped into the following categories:

Healthcare Professionals - Declining appointment times are typical; many patients are less satisfied with information and support obtained from clinicians [3]. Poor communication with physicians and the patient physician relationship may drive users to seek online channels for healthcare information [40]. Diffusing health information has a negative effect on frequency of health care/doctor visits [36].

Behavioural Factors - Online healthcare Information seeking behaviour is associated with healthier people [3]. Perceived poor health status positively affects both frequency and diversity of search for online health information [40].
Chronic disease sufferers whose condition worsens may look for health information online more often overtime and therefore have less doctor visits [36].

It is noteworthy that offline conversations also take place. A study that was conducted by [31] and discusses information seeking in women before visiting their GP and found that depending on whether these conversations were with 'kin' or 'friends', a difference in frequency of GP visits was noted. Essentially the conversations taking place within kinship networks were more intense and resulted in increased GP consultations [31]. The translation of this research to the social media era could be indicative of differing behaviour amongst diverse social groups that transcends the technology. However it does not always follow that patients who have increased healthcare information needs will seek more doctor visits as highlighted by [36].

[25] suggested that the internet is a key influence in changing the balance of 'power' between healthcare professionals and the public. The patient is becoming more knowledgeable and involved in health care decision-making and this is contributing to the de-professionalising of medicine [25]. This professional practice has often related to knowledgeability or expertise. [3] Highlights paternalistic attitudes of some doctors and nurses and the fact that the internet has created a digital divide providing an opportunity for educated, wealthier people to seek alternative healthcare opinions [3]. In particular the use of social networking has also grown from $5 \%$ of all adults in 2005 , to $50 \%$ of all adults by 2011 [43]. According to a health research Institute survey in 2012 one-third of consumers are now using social media for 'health related matters'; preferring community sites over sponsored sites [17]. This implies that patients do not necessarily have to be in poor health to be motivated enough to seek healthcare information. According to the [20] Survey, $39 \%$ of consumers who have a broadband connection at home reported that they had used the internet in the last week for 'finding health information', this figure has increased by 3\% since 2011. Finding health information was highlighted as having the most marked increase since last year indicating a growing trend towards the use of the internet for this purpose [20]. Similarly according to the 'Pew Internet and American Life Project' research, 35\% of Americans say that at one time or another they have gone online specifically to try to find out what medical condition they or someone else might have. People are increasingly using 'ask a doctor' sites, for example $8 \%$ of internet users say they have in the last 12 months posted a health related question online [35]. This research adds further strength to the argument that the internet has increasingly become a compliment to formal healthcare information provision. However a consideration remains that is the law of e-healthcare attrition [6]. In addition some issues remain in relation to the authenticity verification by online health information seekers [8] in addition to the perceived credibility of the internet varied because expertise and trustworthiness were sometimes difficult to determine [12]. Additional consideration is that of the challenge to the authority of the expert causing a perceived deterioration in the physician-patient relationship [19]. 
This literature review captures two themes. First 'Increased healthcare information seeking behaviour will positively influence the patient's healthcare choices'. Several authors have contributed to the idea that patients do have influence over their healthcare choices [13], [36] including compliance with the advice. The question arises as to whether online information seeking has the same influence on patients with chronic health conditions and furthermore how known demographic factors such as gender, age and health status are influencing this.

The second theme captured by the literature review is 'Are patients seeking healthcare information online becoming more demanding of their healthcare compared with patients seeking healthcare information offline?' [10] discussed how social media messages can spread rapidly and influence demand. It is undetermined whether people seek more clinical appointments as a consequence [31], [36]. The other outcome of patients becoming more self efficacious is a possible reduction in reliance on expert intermediaries, and a consequent reduction in requests for healthcare appointments. A, dynamic Intermediation-Disintermediation-Apomediation (D.I.D.A) model has been proposed for this process [7]. The key question is whether online healthcare information searches are simply meeting a demand for personal understanding of the situation they are in, or if information seeking drives patients to seek more doctor appointments to obtain specific treatments.

The following objectives have therefore been developed for this research.

1) To find out which social networks most often used by patients with chronic health conditions.

2) To evaluate how patients with chronic health conditions utilise online healthcare information.

3) To find out how healthcare companies can better engage with patients who live with chronic health conditions.

4) To determine demographic differences in adoption of online social media tools used by patients with chronic health conditions.

\section{METHODOLOGY}

The patient population studied in this research project consists of a sample from $8000+$ patients who have a chronic health condition. Approximately $11 \%$ of these patients are cared for by another individual, either their parent or spouse. A survey was conducted in 2013 as part of a Direct to Patient prescription service audit; this was a requirement by the Department of Health. The resulting patient demographic profile was obtained based on this survey; there were 258 respondents.

The survey indicates that nearly $2 / 3$ of the patients are over 65 years of age. One key factor that determines the degree of internet usage and adoption is age. This might suggest that these patients are relatively low social network users. Onethird of the patients in this survey were female, and according to [36] being female increases your likelihood for online seeking of health information. However [41] found that being middle aged was associated with increased internet use in the context of health care [41]. Taken together this research suggests that the population under study will have a good mix of online and off-line information seekers.

The analysis that follows uses correlation coefficients to test the relationship between two variables [18]. These variables are either positively or negatively correlated and correlations can range in their strength from weak to strong. For this research project weak correlations are taken as below 0.35 (positively or negatively) and correlations above 0.65 (positive or negative) are taken as strong (see, for example, [18]. Correlation analysis explores the extent to which two variables are related to each other without assuming causality. The purpose of performing a correlation is to enable a prediction about one variable based on what is known about another variable; if two variables are strongly correlated then a prediction of the movement of one can be based on the other [18].

For this research project the chosen method will need to produce results that are highly replicable if an understanding is to be gained about a wider chronic long term patient population and their behaviours. To be able to make management decisions relating to the findings of this research a statistical approach will be needed [30]. Hence the quantitative approach will be chosen. The requirement for a large and relatively easy to reach sample frame further supports the quantitative approach; as the $8000+$ patient database allows for a relatively large patient sample to be taken. Therefore the quantitative research method represents the most opportunistic and practicable method. For this research project the probability sampling method that will be chosen is systematic sampling because this is simpler to implement. From the database of $8000+$ patients an initial sampling frame will be selected consisting of patients with chronic conditions only. This excludes short term patients and allows for a systematic sampling method to select a more manageable sample before conducting a survey.

Focusing on a specific disease or condition can produce patients that are not representative of the population. This is because not everyone with a condition has consulted a doctor or specialist about their condition. This might be an important consideration in the context of this research project because patients who seek online or offline healthcare information before seeing the clinician may satisfy their information needs and therefore choose not to see the doctor or specialist. The sample here will only include chronic or long term patients that have consulted with a doctor or specialist thus introducing a degree of bias. Both time and cost constraints prohibit being able to sample patients who have not visited clinicians, as discussed already.

\section{ANALYSIS AND FINDINGS}

The 8000+ database was screened for respondents who were greater than 16 years old and who had ordered products recently meaning that they were current users. Each of the respondents was checked to ensure that they were long-term users by showing that their date of first registration, on the database, was greater than 12 months. This process produced a sampling frame containing 3,767 records. 
Using a stratified sampling technique, where every $6^{\text {th }}$ patient was selected, a sample of approximately 628 subjects was produced and then targeted with the questionnaire. One hundred and forty five questionnaires were completed with an additional 13 responses which were deemed incomplete. The overall response rate was $25 \%$.

The majority of the sample was from the 55+ age brackets with 25\% aged between 55 and 64 and 52\% aged 65+. Table I shows the percentage split of the research sample in comparison with the DOH sample. The gender split across each of the age bands was also fairly evenly split except for the 65+ age band which was male dominated, possibly reflecting disease specific demographic trends such as prostate related conditions in older males.

There was some general hypothesis tested using correlation analysis and $\mathrm{t}$ Test for independent samples. regarding age, self-efficacy and time within this study.

The following are the hypothesis, results and related discussion thereof.

Hypothesis H1A: Age has a positive effect on health information seeking behaviour online

This was tested against high seeking versus low seeking health information. The correlation analysis suggested that there was a negative correlation between age and health information seeking behaviour meaning that as age increased online information seeking decreased. The t-test performed in this analysis suggested that there was not a significant difference $(p=0.068)$ between those patients classified as high information seekers and those classified as low information seekers online. There was not enough evidence to reject the null hypothesis. As such this was a non-significant finding.

According to [3] age, education and wealth were all associated with increased Internet use. Age was a key factor that discriminated between online and off-line information seekers [3]. The internet adoption rate for $65+$ year old patients, the group most represented in this research sample, was twice the level found by the Office for National Statistics (20\% vs $10 \%$ ) [21]. This suggests that patients with chronic health conditions are more likely to use the internet compared to the general population. This did not seem to overcome the negative correlation with age. [31] described a measure of demand as an increase in clinical consultations. What therefore is a true measure of demand? The measure for demand must depend on what outcomes patients expect as a result of healthcare information seeking. This research project repeated [31] work with kinship (off-line) versus friendship networks being compared. However as the number of online general Internet users is so high in this research project (see Fig. 3) it is difficult to screen for 'off-line only' users. The 'Non Significant Finding' therefore may not be a surprise. One of the limitations of this research project was that these patients had already received a diagnosis and treatment. This made measures for of demand for (increased GP consultations) difficult to draw from this cohort.

Hypothesis $\mathrm{H}_{\mathrm{B}}$ : Increased patient self-efficacy is associated with increased demand for healthcare.
TABLE I. RESEARCH SAMPLE OF AgE SPLiT

\begin{tabular}{|l|l|l|}
\hline Age Split (yrs) & Research sample & DOH sample \\
\hline $16-24$ & $2 \%$ & $2 \%$ \\
\hline $25-34$ & $4 \%$ & $2 \%$ \\
\hline $35-44$ & $7 \%$ & $3 \%$ \\
\hline $45-54$ & $9 \%$ & $9 \%$ \\
\hline $55-64$ & $25 \%$ & $20 \%$ \\
\hline $65+$ & $52 \%$ & $64 \%$ \\
\hline
\end{tabular}

This was tested against high versus low demand for healthcare. According to the correlation analysis matrix reported self-efficacy was only linked to age, being negatively correlated $(p=0.397)$. This means that as patients get older their self-efficacy decreases. Whilst there was a good sample size here there was not enough evidence to reject the null hypothesis. The result was therefore not significant.

The key issue with demand for health care is that increasing demand may lead to increase in self-efficacy and this means that patients are less likely to seek health care professional opinions [7]. The findings from this research project suggest that age is negatively correlated with selfefficacy and online information searching; this implies that a younger age group are more likely to search online for health information and take charge of their own health care decisions. This research project concurs with the conclusion in. The author in [3] found in their study that age is negatively correlated with online health information seeking and selfefficacy.

The following hypothesis tests the reported relationship between time on line and demand for healthcare.

Hypothesis: There is a positive relationship between time spent online and demand for healthcare.

This was tested against patients either spending a low amount of time or a high amount of time. Time spent online and demand for health care was supported both by the correlation matrix analysis and by the $t$ test $(p=0.011)$ (one tailed) that was conducted on this research sample. There was evidence to reject the null hypothesis. There was a positive correlation observed between time spent online and demand for health care. Hypothesis H1c also confirmed that there may be a causal link between time spent online and demand for healthcare. This was a significant finding at the $5 \%$ level.

\section{Section 2 Offline and online networks by type}

The following hypotheses were used to test the differences between use of two online and two offline forms of information seeking. The following diagram (Fig. 1) maps the two dimensions of on-line and off-line and the amount of active participation. It shows the four possible outcomes from the combination of these two dimensions.

The following represents the hypothesis D, E, F, G, H, and $\mathrm{I}$, the results and the related discussions.

Hypothesis: Patients seeking healthcare information online are more demanding than patients seeking healthcare information offline. 


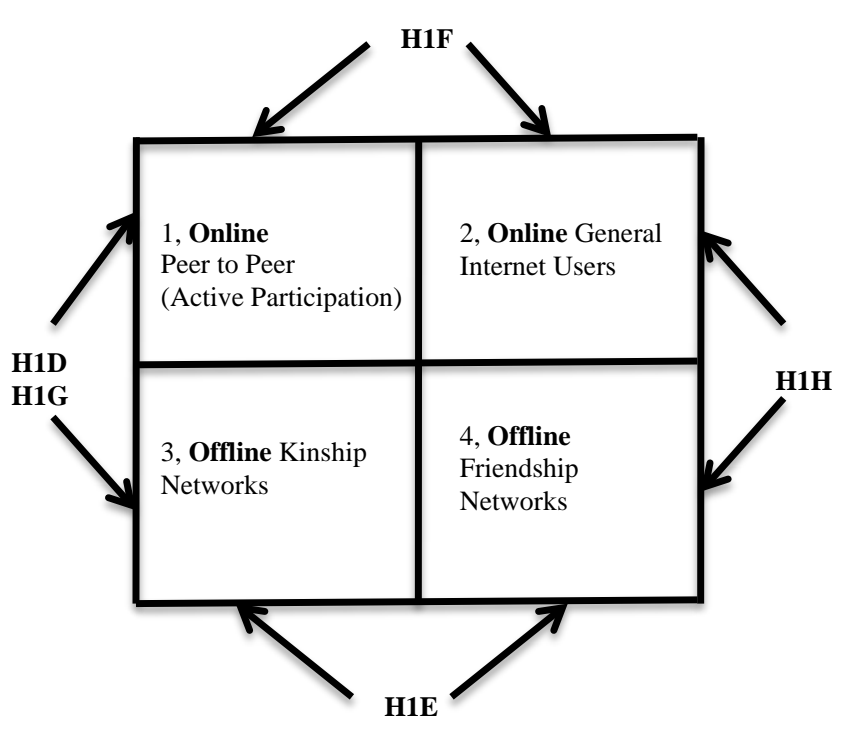

Fig. 1. Offline and Online Networks by Type.

Further exploring demand for healthcare when patients seek healthcare information online using the Chi squared test indicated that there is a statistically significant effect (Chi Squared Test Result: $\mathrm{p}=0.023$ ) on health care demand compared to patients seeking healthcare information offline. As already discussed the only correlation found with online healthcare information seeking through the correlation matrix analysis was with age where a negative correlation was noted. There was evidence to reject the null hypothesis. This was a significant finding.

This is a significant result and concurs with the results obtained in previous studies [36], [13]. [36] found that searching for healthcare information online has a positive, relatively large and statistically significant effect on demand for healthcare and [13] found that online searches resulted in specific demands for cancer treatments. However this result does not rule out the possibility that patients who seek healthcare information offline are simply less interested in healthcare and those who utilise online methods are more interested.

HypothesisH1 $1_{\mathrm{E}}$ : Increased healthcare information seeking behaviour within online peer to peer patient networks results in increased demand for healthcare, compared with offline ‘Kinship’ based networks.

The Chi squared test result confirmed that there was no significant difference between online peer to peer networks and offline kinship networks. From this result offline kinship and online peer-to-peer networks cannot be distinguished and have a similar effect on demand for healthcare (Chi Squared Test Result: $\mathrm{p}=0.487$ ). It is noteworthy that the balance between high and low demand was about equal whereas the split between high and low GP consultation rates in the research sample was 0.62:1 Overall there was not enough evidence to reject the null hypothesis. This was a Nonsignificant finding.
Hypothesis $\mathrm{H} 1_{\mathrm{F}}$ : Patients taking part in offline 'kinship' based networks are more demanding than patients taking part in offline 'friendship' based networks.

The correlation matrix analysis, discussed already, concluded that there was no correlation $(\mathrm{p}=0.500)$ between the tested factors with demand for health care. There was no difference observed between off-line kinship and off-line friendship networks. This was a surprise as this test was a repeat of the research done by [31]. It can only be concluded that either the sample size was inadequate to show a statistically significant difference or there is an effect associated with long term chronic conditions which was not evident in the research conducted by [31] and her team. Overall there was not enough evidence to reject the null hypothesis. This was a Non-significant finding.

HypothesisH1 ${ }_{\mathrm{G}}$ : Patients taking part in online peer to peer networks are more demanding than patients who don't participate in online networks.

The correlation matrix highlighted sharing and engaging online, in other words participating in peer to peer networks, as being positively correlated (Chi Squared Test Result: P value $=0.723$ ) to online information seeking. However a more detailed Chi Squared test did not find a relationship. There was not enough evidence to reject the null hypothesis. This was a Non-significant finding.

HypothesisH1 ${ }_{\mathrm{H}}$ : The use of non-participatory online networks results in greater demand for healthcare compared with offline friendship based networks.

Chi Squared Test Result: $\mathrm{P}$ value $=0.909$. The Chi squared test used to compare non-participatory online networks with off-line friendship based networks showed that there was not a statistically significant difference between these two network types. This may be an expected result if there was no 'internet effect' on demand for healthcare when comparing two similar networks whether they be online or offline. A better understanding of the 'internet effect' can be gained by contrasting this result with hypothesis $\mathrm{H} 1_{\mathrm{E}}$ which similarly attempted to measure whether there was an 'internet effect' or whether there was a 'social network effect' on demand for healthcare. There was not enough evidence to reject the null hypothesis. This was a Non-significant finding.

Hypothesis $\mathrm{H} 1_{\mathrm{I}}$ : The use of social media tools increases demand for specific treatments compared to offline networks.

The Chi squared test was used to establish whether social media tools increase demand for specific treatments. A comparison was made between two cohorts; one that adopted social media tools and one that did not. Whilst there was no significant difference found (Chi Squared Test Result: P value $=0.894$ ), it could be seen that the cohort that adopted online tools within this research project was small for both high and low demand $(n=10$ and $n=11$ respectively). There was not enough evidence to reject the null hypothesis. This was a Nonsignificant finding. 
Demand for specific treatments as a result of using social media tools represents a significant opportunity for commercial companies. The author in [13] highlighted that this was indeed the case for patients with colon cancer (S. W. Gray, et al., 2009). This research project specifically examined the demand effect for patients with chronic conditions hypothesis $\mathrm{H} 1_{\mathrm{I}}$ above. The measure for demand in this instance, GP consultations, was appropriate as patients who want specific treatments as a result of searching for information online would need to see their clinician. The null hypothesis was accepted. This implies that this patient group are not demanding specific treatments as a result of online searches. The author in [37] in his comparison of online with offline information seeking in older patients and suggests that healthcare decisions based on information obtained 'offline' are more probable in this patient group [37]. Unlike the colon cancer study [13], this patient group was older and perhaps seeking healthcare information offline is more appropriate. This research project explored offline kinship and friendship networks to see if there was a link between offline information searches and healthcare demand (Hypothesis $\mathrm{H} 1_{\mathrm{D}}$ ), however none was found for this research sample. It is therefore not possible to confirm either [13] or [37] research findings for patients with chronic conditions. This may be that the number of active participants in peer to peer networks in this survey was low as discussed in the limitations of this research.

\section{Discussion of findings}

Hypothesis $H 1_{D}$ looked at online versus off-line information seeking and its effect on demand. Based on hypothesis $\mathrm{H} 1_{\mathrm{D}}$ this research project supports the idea that utilising the internet compared to offline methods for seeking healthcare information does have a significant effect on demand for healthcare. The result from this research project suggests that some patients seek healthcare information online and in particular younger patients gain a degree of selfefficacy which potentially results in these patients seeking more GP appointments. According to [26], "internet users are more likely to expect they could obtain reliable information about health conditions compared to non internet users" [26]. This result supports the case for a higher degree of motivation amongst online information seekers to seek healthcare information and then do something with that information, for example seeking a clinician appointment. This confirms the results obtained by [36] in that searching for healthcare information online has a positive, relatively large and statistically significant effect on demand for healthcare [36].

Taking Hypothesis $\mathrm{H} 1_{\mathrm{E}}$ as a non-significant result; implies that kinship and online peer-to-peer patient communities have no significant difference in the way they act in the context of demand for healthcare. The results from hypothesis $\mathrm{H} 1_{\mathrm{E}}$, nonsignificant result, when combined with Hypothesis $\mathrm{H} 1_{\mathrm{E}}$ infers that there is no 'social network affect' on demand for healthcare, whether that be peer-to-peer or kinship based.

Hypothesis $\mathrm{H} 1_{\mathrm{E}}$ was intended to repeat of the work done by [31]. However in comparing the kinship and the friendship networks this hypothesis did not show a statistically significant (off-line) effect.
This again raises the question as to the validity of demand as measured by GP consultation rates. Another explanation is that perhaps patients seeking information online in this research project simply want to explore their current acute condition, a condition that is unrelated to their underlying chronic condition. Overall, however, this research project found no evidence to support peer-to-peer or kinship based influence on demand for healthcare. This concurs with a review [9] which failed to find robust evidence for the benefits of virtual communities about health outcomes [9].

The remaining tests covered by hypotheses H1F, H1G, and $\mathrm{H} 1 \mathrm{H}$ resulted in non-significant results. Therefore it is not possible to accept any difference in these methods of information seeking. In particular it is not possible to find a difference between the use of peer to peer networks and general internet searches in increasing demand for health services. This lack of significance is a challenge to the development of the use of peer to peer sites in this context. The following test therefore investigates the demand for specific treatments in the use of social media.

The table (Table II) highlights the summary outcomes of the correlation analysis. What follows is a detailed discussion on the results.

\section{Results for Research Objective 1:}

To find out which social networks most often used by patients with chronic health conditions.

TABLE II. SUMMARY RESPONSE FROM THE CORRELATION ANALYSIS

\begin{tabular}{|c|c|c|c|c|}
\hline Factor & Correlation & $\begin{array}{l}\text { Pearson's } \\
\text { Correlation } \\
\text { Coefficient }\end{array}$ & $\begin{array}{l}\text { Strength of } \\
\text { Correlation }\end{array}$ & $\begin{array}{l}\text { Sig. } \\
\text { (p value) }\end{array}$ \\
\hline \multirow[b]{2}{*}{ Age } & Self-Efficacy & -0.437 & Moderate & $\begin{array}{l}\mathrm{P}= \\
0.014 *\end{array}$ \\
\hline & $\begin{array}{l}\text { Online } \\
\text { Information } \\
\text { Seeking }\end{array}$ & -0.414 & Moderate & $\begin{array}{l}\mathrm{P}= \\
0.021 *\end{array}$ \\
\hline \multirow{3}{*}{$\begin{array}{l}\text { Online } \\
\text { Info } \\
\text { Seeking }\end{array}$} & $\begin{array}{l}\text { Time Spent } \\
\text { Online }\end{array}$ & 0.386 & Moderate & $\begin{array}{l}\mathrm{P}= \\
0.032 *\end{array}$ \\
\hline & $\begin{array}{l}\text { Sharing } \\
\text { Health } \\
\text { Information } \\
\text { Online }\end{array}$ & 0.404 & Moderate & $\begin{array}{l}\mathrm{P}= \\
0.024^{*}\end{array}$ \\
\hline & $\begin{array}{l}\text { Engaging } \\
\text { With Others } \\
\text { Online }\end{array}$ & 0.371 & Moderate & $\begin{array}{l}\mathrm{P}= \\
0.041^{*}\end{array}$ \\
\hline \multirow{2}{*}{$\begin{array}{l}\text { Offline } \\
\text { Info } \\
\text { Seeking }\end{array}$} & $\begin{array}{l}\text { Sharing } \\
\text { Health } \\
\text { Information } \\
\text { Online } \\
\end{array}$ & -0.556 & Moderate/Strong & $\begin{array}{l}\mathrm{P}= \\
0.001 * *\end{array}$ \\
\hline & $\begin{array}{l}\text { Engaging } \\
\text { With Others } \\
\text { Online }\end{array}$ & -0.523 & Moderate & $\begin{array}{l}\mathrm{P}= \\
0.002 *\end{array}$ \\
\hline $\begin{array}{l}\text { Sharing } \\
\text { Health } \\
\text { Info } \\
\text { Online } \\
\end{array}$ & $\begin{array}{l}\text { Offline Social } \\
\text { Networks }\end{array}$ & -0.367 & Moderate/Weak & $\begin{array}{l}\mathrm{P}= \\
0.043^{*}\end{array}$ \\
\hline $\begin{array}{l}\text { Engaging } \\
\text { With } \\
\text { Others } \\
\text { Online }\end{array}$ & $\begin{array}{l}\text { Offline Social } \\
\text { Networks }\end{array}$ & -0.404 & Moderate & $\begin{array}{l}\mathrm{P}= \\
0.024 *\end{array}$ \\
\hline
\end{tabular}


From the research sample the respondents could be attributed to each of four categories that are online P2P users, Online general users, Offline Kinship, Offline friendship networks and Offline social networks were easy to identify. However it was difficult to establish whether respondents using 'offline' networks ever used the internet for health purposes. Some patients inevitably do and this is reflected by a large ‘online general users' group.

Referring to section 2.4 and the D.I.D.A. model it was noted that patients who were empowered, ie had a high degree of self-efficacy, may demand more healthcare. According to the D.I.D.A. model if the patient has a positive experience with 'apomediation' websites, their knowledge or self-efficacy will increase and the patient will feel more empowered. Consequently their reliance on clinical experts will decrease. Table III highlights websites that respondents in this research project described as 'favourites' and therefore have the potential to act as apomediary websites. Of note is that this research uncovered that very few patients (just over 5\%) said they regularly visited a 'favourite' health website.

Apomediary websites are used to enable patients to become both more self efficacious and autonomous meaning that they depend less on clinicians, known as intermediaries in the Eysenbach's D.I.D.A. model [7]. The principals of the D.I.D.A. model mean that clinicians today are gatekeepers to treatment whereas previously they were also gatekeepers for information. This information is now being made available online. As internet adoption increases and healthcare information seeking becomes more prevalent so then does the empowering force of the internet on the demand for specific treatments.

Summary Response: Evidence to support adoption of both online and offline networks, however scanty evidence to support adoption of favourite or 'apomediary' websites.

TABLE III. LIST OF ‘APOMEDIARY’ WEBSITES

\begin{tabular}{|l|l|l|}
\hline Website & Description & $\begin{array}{l}\text { Number } \\
\text { Cited }\end{array}$ \\
\hline (http://www.apparelyzed.com) & $\begin{array}{l}\text { Spinal cord injury } \\
\text { patient website }\end{array}$ & 2 \\
\hline (http://hsionline.com) & $\begin{array}{l}\text { The Health Science } \\
\text { Institute }\end{array}$ & 1 \\
\hline $\begin{array}{l}\text { (http://www.dbh.nhs.uk/patient } \\
\text {-information-leaflets/) }\end{array}$ & $\begin{array}{l}\text { NHS patient } \\
\text { information leaflets }\end{array}$ & 4 \\
\hline$\underline{\text { http://www.mssociety.org.uk }}$ & $\begin{array}{l}\text { Multiple Sclerosis } \\
\text { Society }\end{array}$ & 3 \\
\hline$\underline{\text { https://www.gov.uk/governmen }}$ & $\begin{array}{l}\text { The Department of } \\
\text { Health }\end{array}$ & 1 \\
\hline$\underline{\text { health }}$ & $\begin{array}{l}\text { Multiple Sclerosis } \\
\text { online magazine }\end{array}$ & 1 \\
\hline$\underline{\text { http://www.ms- }}$ uk.org/newpathways & $\begin{array}{l}\text { NHS health } \\
\text { information }\end{array}$ & 1 \\
\hline$\underline{\text { http://www.nhsdirect.nhs.uk }}$ & $\begin{array}{l}\text { Spina Bifida and } \\
\text { hydrocephalus } \\
\text { support charity }\end{array}$ & 1 \\
\hline$\underline{\text { http://www.shinecharity.org.uk }}$ & $\mathbf{8}$ \\
\hline Total & & \\
\hline
\end{tabular}

\section{Results for Research Objective 2:}

To evaluate how patients with chronic health conditions utilise online healthcare information.

It was concluded from hypothesis $H 1_{F}$ and $H 1_{G}$ that patients who spend significant time on the internet experience an increase in demand for healthcare. Seeking information online made patients more demanding than patients who seek healthcare information offline. This objective, however, seeks to understand how patients with chronic health conditions use online healthcare information; i.e. does it lead to specific requests for treatment or is it used to comment on other patients' health situation?

Fig. 2, highlights the extent patients with chronic conditions seek healthcare information online and offline. In this research project there was a 60:40 spilt between online and offline information seekers in favour of online information seekers.

Patients with chronic conditions, approximately 19\%, view other patients' experiences through online communities, and approximately half of this group will either share their own health experience or comment on others health experiences through these communities. See Fig. 3:

Disclosure of new treatments, such as a possible cure for multiple sclerosis, can drive popularity of social media; it follows that like-minded consumers come together and potentially influence other patients through viral marketing [10]. [4] found that social networking provides 'social incentives' meaning that there is a motivation for patients partaking in the sharing of information and engaging with others online [4].

Summary Response: A relatively small but significant proportion of patients view, share and engage online with other patients though patient led communities.

\section{Objective 3}

To find out how healthcare companies can better engage with patients who live with chronic health conditions.

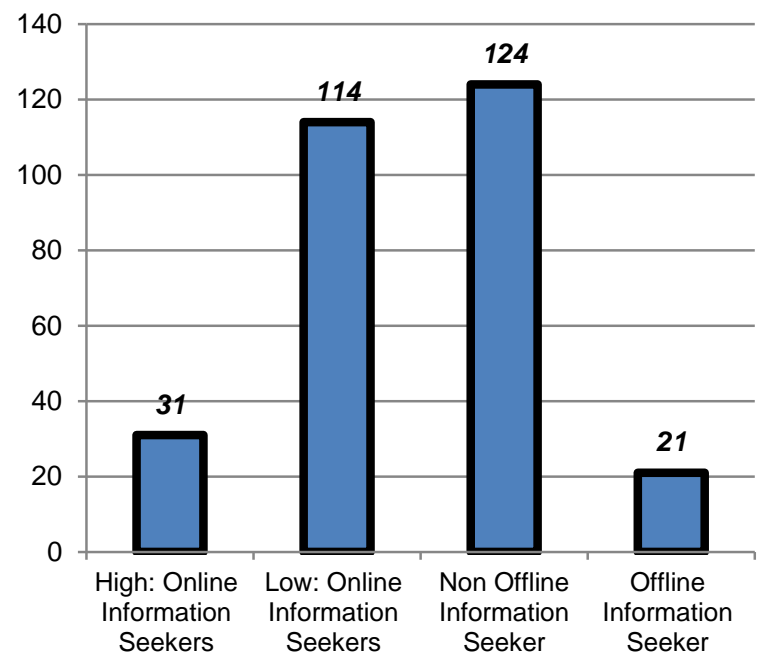

Fig. 2. Online and Offline Information Split by Level. 


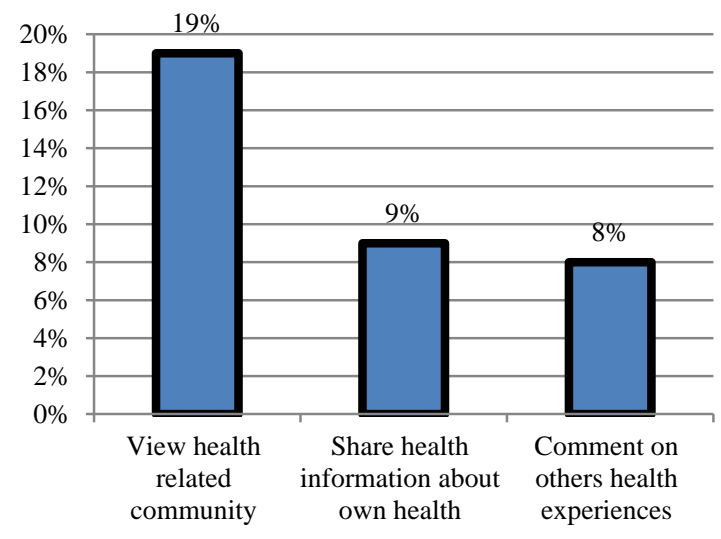

Fig. 3. Viewing, Sharing and Engaging Online.

Companies operating in health care could influence consumer behaviour in several ways based on the findings within this research project. Patients or consumers are potentially most open to influence if they are high internet users, or prefer to take part in peer to peer interactions online with other like-minded patients rather than sharing their symptoms within offline kinship based networks. It is known from this research that patients who use online search methods demand more healthcare than patients who adopt offline methods. It is also known that the more time a patient spends online the more demanding the patient becomes. Patient forums are popular with some patients and indeed these forums or communities encourage patients to spend more time online. Whilst this research project failed to show a correlation with peer to peer networks and demand for healthcare; a relationship between time spent online and $\mathrm{P} 2 \mathrm{P}$ network usage was shown to exist, see Table IV.

Patients using P2P communities spend more time online. This may be a consequence, albeit not proven in this research project, that patients who use these networks may be more demanding of healthcare as a result of the time spent online. If healthcare companies encourage patients to utilise P2P communities via their own websites then this may encourage increased time spent online and consequently encourage an increase in demand for healthcare e.g. demanding specific treatments.

TABLE IV. PeER to PeER usage AcCording to Time SPENT OnLine

\begin{tabular}{|c|c|c|c|c|c|c|c|}
\hline $\begin{array}{l}\text { Actual } \\
\text { Result }\end{array}$ & $\begin{array}{l}\text { P2P } \\
\text { non } \\
\text { user }\end{array}$ & $\begin{array}{l}\text { P2P } \\
\text { User }\end{array}$ & Total & $\begin{array}{l}\text { Exp. } \\
\text { Result }\end{array}$ & $\begin{array}{l}\text { P2P } \\
\text { non } \\
\text { user }\end{array}$ & $\begin{array}{l}\text { P2P } \\
\text { User }\end{array}$ & Total \\
\hline $\begin{array}{l}\text { Time } \\
\text { Spent } \\
\text { Online } \\
= \\
\text { High }\end{array}$ & 11 & 9 & 20 & $\begin{array}{l}\text { Time } \\
\text { Spent } \\
\text { Online } \\
= \\
\text { High }\end{array}$ & 16 & 4 & 20 \\
\hline $\begin{array}{l}\text { Time } \\
\text { Spent } \\
\text { online } \\
=\text { low }\end{array}$ & 101 & 18 & 119 & $\begin{array}{l}\text { Time } \\
\text { Spent } \\
\text { online } \\
=\text { low }\end{array}$ & 96 & 23 & 119 \\
\hline Total & 112 & 27 & 139 & Total & 112 & 27 & 139 \\
\hline
\end{tabular}

* significant at $1 \%$ level
Summary Response: Evidence to support the link between P2P network usage and time spent online but insufficient causal evidence to support P2P network usage and increase demand for healthcare.

\section{Objective 4}

To determine demographic differences in adoption of online social media tools used by patients with chronic health conditions.

TABLE V. GENDER SPECIFIC INTERNET ADOPTION RATES

\begin{tabular}{|l|l|l|l|}
\hline Gender & $\begin{array}{l}\text { High Internet } \\
\text { Adoption (n) }\end{array}$ & $\begin{array}{l}\text { Low Internet } \\
\text { Adoption (n) }\end{array}$ & $\begin{array}{l}\text { Percentage High } \\
\text { Adoption }\end{array}$ \\
\hline Female & 12 & 43 & $22 \%$ \\
\hline Male & 19 & 68 & $22 \%$ \\
\hline Total & 31 & 111 & $22 \%$ \\
\hline
\end{tabular}

The table (Table V) highlights the fact that there were no gender differences in internet adoption rates in this research sample. The author in [15] found that females were more likely to use the internet for health related information than males and were more likely to belong to patient support groups [15]. This effect was not observed in this research project, possibly a reflection of the smaller size of the female segment.

TABLE VI. GENDER SPECIFIC SELF EFFICACy I.E SEEKING DiSEASE AND TREATMENT INFORMATION

\begin{tabular}{|l|l|l|l|l|l|l|}
\hline $\begin{array}{l}\text { Statistical } \\
\text { Comparis } \\
\text { on }\end{array}$ & $\begin{array}{l}\text { Variabl } \\
\text { e }\end{array}$ & $\begin{array}{l}\text { Compar } \\
\text { ison }\end{array}$ & $\begin{array}{l}\text { Sampl } \\
\text { e Size }\end{array}$ & $\begin{array}{l}\text { Mea } \\
\mathbf{n}\end{array}$ & $\begin{array}{l}\text { Vari } \\
\text { ance }\end{array}$ & $\begin{array}{l}\text { P value } \\
\text { one tailed }\end{array}$ \\
\cline { 1 - 5 } $\begin{array}{l}\text { t Test } \\
\text { independen } \\
\text { t samples }\end{array}$ & $\begin{array}{l}\text { Gender } \\
\text { \& Self } \\
\text { Efficac } \\
\mathrm{y}\end{array}$ & Female & $\mathrm{n}=55$ & 3.51 & 0.82 & \multirow{2}{*}{$\mathrm{p}=0.063$} \\
\cline { 3 - 6 } & & Male & $\mathrm{n}=87$ & 3.10 & 1.26 & \\
\hline
\end{tabular}

This table (Table VI) illustrates gender specific differences in self-efficacy, known to be a key factor in demanding more healthcare information and potentially asking the GP for specific treatments. Statistically there are no gender specific effects for self-efficacy.

Summary Response: There was evidence to support increased internet adoption rates according to defined age bands, indicating that being unwell increases likelihood of internet use compared to the general population. There were no gender differences noted.

\section{Research Question}

Have online social media tools affected demand for healthcare in patients who experience chronic medical conditions?

This research project provides evidence to support the idea that searching for healthcare information and spending more time online has positive effects on demand for healthcare amongst patients who live with chronic medical conditions. Patients who have chronic conditions spend more time online than the general population. Patients who take part in online peer to peer communities are more trusting of healthcare 
information obtained in an online setting. There was a causal link between time spent online and Peer to Peer network adoption. Spending time online was shown to have a positive effect on demand for healthcare. This research project also highlighted that younger patients are likely to become more self-efficacious and this potentially translates into a greater autonomy relating to their healthcare treatment decisions. In future these younger patients will age and replace the older generations with their social networking preferences. These patients will spend increasing time on peer to peer communities and as a consequence their demand for healthcare in general for treatments specifically will increase. The patients of the future will therefore depend less on their doctor for healthcare or product information and see the doctor as simply a gatekeeper for accessing treatments. The doctors of the future will experience patients who are more demanding, not necessarily for health information but for specific treatments.

TABLE VII. OVERVIEW OF HyPOTHESIS, TEST TYPE, P VALUES AND OUTCOME

\begin{tabular}{|c|c|c|c|c|}
\hline Нур & Detail & $\begin{array}{l}\text { Statistical } \\
\text { Comparison }\end{array}$ & $P$ value & $\begin{array}{l}\text { Null } \\
\text { Hypothesis } \\
\text { Accepted or } \\
\text { Rejected } \\
\end{array}$ \\
\hline $\mathrm{H} 1_{\mathrm{A}}$ & $\begin{array}{l}\text { Age has a positive } \\
\text { effect on health } \\
\text { information seeking } \\
\text { behaviour online }\end{array}$ & $\begin{array}{l}\mathrm{t} \text { Test } \\
\text { independent } \\
\text { samples }\end{array}$ & $\mathrm{p}=0.068$ & Accepted \\
\hline $\mathrm{H} 1_{\mathrm{B}}$ & $\begin{array}{l}\text { Increased patient } \\
\text { Self Efficacy is } \\
\text { associated with } \\
\text { increased demand } \\
\text { for healthcare }\end{array}$ & $\begin{array}{l}\text { Linear } \\
\text { Regression }\end{array}$ & $\mathrm{p}=0.397$ & Accepted \\
\hline $\mathrm{H} 1_{\mathrm{C}}$ & $\begin{array}{l}\text { Patients taking part } \\
\text { in increased } \\
\text { healthcare } \\
\text { information seeking } \\
\text { behaviour within } \\
\text { online peer to peer } \\
\text { patient networks } \\
\text { seek more GP } \\
\text { consultations } \\
\text { compared with } \\
\text { patients using } \\
\text { offline 'Kinship' } \\
\text { based networks }\end{array}$ & $\begin{array}{l}\text { Chi Squared } \\
\text { Test }\end{array}$ & $\mathrm{p}=0.487$ & Accepted \\
\hline $\mathrm{H} 1_{\mathrm{D}}$ & $\begin{array}{l}\text { Patients taking part } \\
\text { in offline 'kinship' } \\
\text { based networks are } \\
\text { more demanding } \\
\text { than patients taking } \\
\text { part in offline } \\
\text { 'friendship' based } \\
\text { networks }\end{array}$ & $\begin{array}{l}\text { Chi Squared } \\
\text { Test }\end{array}$ & $\mathrm{p}=0.500$ & Accepted \\
\hline $\mathrm{H} 1_{\mathrm{E}}$ & $\begin{array}{l}\text { Patients taking part } \\
\text { in online peer to } \\
\text { peer networks are } \\
\text { more demanding } \\
\text { than patients who } \\
\text { don't participate in } \\
\text { online networks }\end{array}$ & $\begin{array}{l}\text { Chi Squared } \\
\text { Test }\end{array}$ & $\mathrm{p}=0.728$ & Accepted \\
\hline
\end{tabular}

\begin{tabular}{|c|c|c|c|c|}
\hline $\mathrm{H} 1_{\mathrm{F}}$ & $\begin{array}{l}\text { There is a positive } \\
\text { relationship } \\
\text { between time spent } \\
\text { online and demand } \\
\text { for Healthcare }\end{array}$ & $\begin{array}{l}\mathrm{t} \text { Test } \\
\text { independent } \\
\text { samples }\end{array}$ & $\begin{array}{l}\mathrm{p}= \\
0.011^{*}\end{array}$ & Rejected \\
\hline $\mathrm{H} 1_{\mathrm{G}}$ & $\begin{array}{l}\text { Patients seeking } \\
\text { healthcare } \\
\text { information online } \\
\text { are more } \\
\text { demanding than } \\
\text { patients seeking } \\
\text { healthcare } \\
\text { information offline }\end{array}$ & $\begin{array}{l}\text { Chi Squared } \\
\text { Test }\end{array}$ & $\begin{array}{l}\mathrm{p}= \\
0.023 *\end{array}$ & Rejected \\
\hline $\mathrm{H} 1_{\mathrm{H}}$ & $\begin{array}{l}\text { The use of non- } \\
\text { participatory online } \\
\text { networks results in } \\
\text { greater demand for } \\
\text { healthcare } \\
\text { compared with } \\
\text { offline friendship } \\
\text { based networks }\end{array}$ & $\begin{array}{l}\text { Chi Squared } \\
\text { Test }\end{array}$ & $\mathrm{p}=0.909$ & Accepted \\
\hline $\mathrm{H} 1_{\mathrm{I}}$ & $\begin{array}{l}\text { The use of social } \\
\text { media tools } \\
\text { increases demand } \\
\text { for specific } \\
\text { treatments } \\
\text { compared to offline } \\
\text { networks }\end{array}$ & $\begin{array}{l}\text { Chi Squared } \\
\text { Test }\end{array}$ & $p=0.894$ & Accepted \\
\hline
\end{tabular}

The table (Table VII) highlights the hypotheses tested, the test, result and the outcome pertaining to the acceptance or rejection of the hypotheses.

\section{LIMITATIONS OF RESEARCH}

The sample targeted represented patients that all had chronic long term conditions. This was identified by them being on treatment for a significant length of time; unfortunately this also meant that these patients were not recently started on treatment. Therefore the possibility exists that these patients might have referred to health conditions that were not related to their primary diagnosis when completing this questionnaire. This could have affected their interpretation of the questions which would have a negative effect on the validity of the results obtained.

The literature clearly suggested that there were differences in demand noticed as a result of the use of social media tools. However there remains the possibility that patients may perceive to have their demand for healthcare satisfied through their online search for healthcare information. Thus resulting; however, in a decrease in essential GP consultation, a key outcome of demand. However there is a significant likelihood that misinformation and mis-diagnosis can result in further complications due to the reduction of GP consultations.

For companies in healthcare that currently have no social media policy, any patients registered on the company's Direct To Patient service, would find very limited information on products through social media. In contrast other manufacturers in the healthcare sector that do have a social media policy may be at an advantage. Potentially this creates a bias in so much that patients who are familiar with social media tools may 'prefer' products from manufacturers who have a social media policy. This introduces a potential bias in this study whereby 
the testing of patients from other healthcare Direct To Patient Services with social media provision was not undertaken.

\section{CONCLUSION}

1) The changing doctor-patient relationship: From this research paper the link between age and sharing and engaging online was unproven. Age was however negatively correlated with online information seeking behaviour and self-efficacy. This implies that the younger patient is taking more control of their health and seeking more information online, a trend that is likely to increase as these young patients become old patients.

2) The patient as the new decision maker: More than ever before it is possible to listen to the consumers' voice through either producer or community led communities and acting on their feedback. Involving the patient in the product or healthcare decision making process serves to not only add value but can improve healthcare outcomes especially patient compliance. In an attempt to overcome poor compliance it has been suggested that patient involvement through the concordance model would achieve greater self-efficacy [39]. A concordance between the expert and the patient requires the mutual adoption of the treatment regime. This mutuality often requires a positive efficacious embrace of the adopted solution. The consequence of this is that patients often are now much more demanding of their healthcare professional; appointment times are however increasing due to Covid and demands upon healthcare professionals are ever more stretched meaning that the burden of responsibility for patient knowledge and healthcare choices falls increasingly upon the patient [3]. The key here being that the patient can contribute more, regarding symptoms that can better inform the GP to enable more accurate diagnosis. As already discussed selfefficacy is negatively correlated with age but was not shown to be related to demand for healthcare in this research project. The issue of measuring demand was discussed and a further understanding of outcomes expected as a result of online searches is needed.

3) A model for seeking Health information: Eysenbach's D.I.D.A. model explored the idea of relying on apomediaries [7]. These may be specific 'one stop shop' websites or peer to peer networks. It was apparent from this research project that patients taking part in patient peer to peer communities either online or offline were no more demanding in terms of GP consultation requests. There was no 'network effect' observed offline which contradicted [31] work. It can be concluded that modern day healthcare information seekers behave differently to the kinship of friendship networks observed by [31].

4) Healthcare information seeking increases demand for health care: Spending more time online, from this research project, was shown to have a positive effect on demand for healthcare. It was also demonstrated that patients seeking healthcare information online were more demanding than patients who seek healthcare information offline, meaning that patients who spend time online and seek healthcare information are likely to seek more GP consultations. However whilst these patients are consulting more with their GP they are not, according to this research, demanding specific treatments.

\section{Recommendations}

Concerning the patient population in this study; patients who experience ongoing changes in their treatments as a result of their condition (e.g. MS patients - whose condition evolves over time) may have been a better group of respondents to judge the effectiveness of social media and its influence. Given the difficulties in determining demand for healthcare inherent in this research project, a re-examination of the research philosophy is suggested. The chosen philosophy was positivism as this emphasised the value of predicting outcomes of the research so that these variables might be controlled in future. According to [36] at the root of the positivist research philosophy is the law of cause and effect [36].

Examples of cause and effect in this research project are:

1) Social networks 'cause' an increase in healthcare information seeking behaviour - the 'effect'

2) Age 'causes' increase in healthcare information seeking behaviour - the 'effect'

3) Spending time online 'causes' an increase in demand for healthcare - the 'effect'

Essentially, and as discussed previously, assumptions were made about what causes demand and what 'demand' is in the context of healthcare. Therefore a better way of determining the factors or 'causes' that are likely to predict the outcome, the 'effect' is needed. According to [36] greater organisational or online market complexity, with the online/offline environment, would lead towards an interpretivist approach [36]. Referring to interpretivism makes it necessary to conduct research in the online environment in order to understand what is going on among the markets 'social actors'; people who play a part on the stage of online and offline information seeking. Building on the correlation analysis the demand for healthcare could be further explored using an interpretivist approach to better understand what patients with chronic conditions are looking for.

This research project represents a snapshot in time of people's current internet adoption rates. Therefore as age and usage of technology increases in future, the age correlation is expected to become less negative meaning that patients across all levels will have greater self-efficacy in their online searching behaviours. This means that the younger patient with a chronic condition will, if they stay with the company's Healthcare's DTP service, become the next older patient generation and as such be more accustomed to using online search tools.

The author in [23] suggests that a stronger bond between producer led and customer (the patient) led community interactions will better enable both an understanding and adaption of the marketing message. The findings from this research project suggest that peer to peer communities are more trusting of online information and spend more time 
online; typically these patient groups are patients with chronic conditions. These patient led communities represent an opportunity to augment the traditional direct marketing interface which represents a producer: customer interaction. This may take the form of directing patients to the company's own website which may not contain traditional marketing or product related information but rather contains the resources required for the patient to begin to see the company website as a 'one stop shop' or favourite website, known as an apomediary website. This would provide the patient with the patient networks and information needed to help the patient form positive impressions of the website, and the company that produced it. Ultimately the patient will express a preference for the company's products once they visit their GP.

\section{FUTURE RESEARCH}

From this research project it is clear that more work would need to be done to corroborate the motivation patients have for seeking healthcare information online and how this translates into more demand for healthcare. Thus:

Establishing the motives for healthcare information seeking through a qualitative analysis and structured interviews would prove insightful.

Exploring the extent to which patients with chronic conditions depend on the internet and social media tools would also prove invaluable.

This research project looked at patients who had already received their primary diagnosis. What happens to patients before that diagnosis? Is it possible that patients who were prolific internet users prior to receiving their initial diagnosis and once established on treatment their internet usage waned? This research project was unable to establish internet and social media tool usage prior to the patients receiving treatments.

It is well known that an established friend on Facebook follows an 'offline to online' trend with people making friends offline first and then later adding them online [27]. Does the same 'offline to online' affect exist with patients who have long term conditions such as spinal cord injury? For example do these patients later connect online with other patients met 'offline' within spinal cord units?

According to [22] Social psychologists make a distinction between different attitude levels with the deepest being referred to as personality, followed by values then attitudes with the most superficial being referred to as opinions [22]; establishing the effect of the patients' personality on social media usage, for example the degree of extroversion or introversion. Could this be a motivation to experiment with seeking online health information rather than utilizing established offline methods? Conversely introversion is associated with a greater dependence on Facebook for communicating with and establishing friends (Orr et al.,2009); could the same influence exist with patients with chronic conditions?

It would be valuable to establish a long term view of how patients with chronic conditions use social media tools post
Covid, particularly as this study was pre-Covid. This research project took a cross sectional view on social media adoption. A longitudinal study could follow the patient's use of social media tools from before diagnosis to a time period where the patient was established in terms of both their condition and treatment. This would give invaluable insights into the patient's use of social media tools.

This research project only looked at patients with long term conditions; it would also be helpful to consider patients with short term acute conditions to establish differences in motivations for seeking healthcare information and support.

An underlying tenet of this study was that use of social media tools affects demand for healthcare. It was assumed that demand could only be in the form of seeking clinician appointments or specifically asking for treatments. Additional needs affecting demand may also exist particularly with patients using peer to peer networks.

\section{REFERENCES}

[1] Al-Qahtani, M.F., Al-Saffar, A.K., Alshammasi, A., Alsanni, G., Alyousef, Z.T., \& Alhussaini, M. (2018). Social media in healthcare: Advantages and challenges perceived by patients at a teaching hospital in eastern province, Saudi Arabia. Saudi Journal for Health Sciences, 7, $116-120$.

[2] Benetoli, A., Chen, T. F., \& Aslani, P. (2017). Consumer Health-Related Activities on Social Media: Exploratory Study. Journal of medical Internet research, 19(10), e352. https://doi.org/10.2196/jmir.7656

[3] Cotton, S. R., \& Gupta, S. S. (2004). Characteristics of online and offline health information seekers and factors that discriminate between them.Social science \& medicine, 59(9).

[4] Crosier, B. S., Webster, G. D., \& Dillon, H. M. (2012).Wired to connect: Evolutionary psychology and social networks.Review of General Psychology, 16(2).

[5] Davis, T. F. (2012). What marketers say about working online.McKinsey Quarterly.

[6] Eysenbach, G. (2005). The law of attrition. Journal of Medical Internet Research, 7(1).

[7] Eysenbach, G. (2008). Medicine 2.0: social networking, collaboration, participation, apomediation, and openness. Journal of Medical Internet Research, 10(3).

[8] Eysenbach, G., \& Kohler, C. (2002). How do consumers search for and appraise health information on the world wide web? Qualitative study using focus groups, usability tests, and in-depth interviews.BMJ, 324(7337).

[9] Eysenbach, G., Powell, J., Englesakis, M., Rizo, C., \& Stern, A. (2004). Health related virtual communities and electronic support groups: systematic review of the effects of online peer to peer interactions. BMJ, 328(7449).

[10] Gabarron, S.E., Fernandez-Luque, L., \&Armayones, M. (2012). Social media in health -- what are the safety concerns for health consumers? Health Information Management Journal, 41(2), 30-35.

[11] Girard, T., Dion P., (2010), Validating the search, experience, and credence product classification framework. Journal of Business Research, Vol.63, pp1079-1087.

[12] Gray, N. J., Klein, J. D., Noyce, P. R., Sesselberg, T. S., \&Cantrill, J. A. (2005). Health information-seeking behaviour in adolescence: the place of the internet. Social science \& medicine, 60(7), 1467-1478

[13] Gray, S. W., Armstrong, K., DeMichele, A., Schwartz, J. S., \&Hornik, R. C. (2009).Colon cancer patient information seeking and the adoption of targeted therapy for on-label and off-label indications.Cancer, 115(7).

[14] Hagg, E., Dahinten, V. S., \& Currie, L. M. (2018). The emerging use of social media for health-related purposes in low and middle-income countries: A scoping review. International journal of medical informatics, 115, 92-105. https://doi.org/10.1016/j.ijmedinf.2018.04.010 
[15] Hesse, B. W., Nelson, D. E., Kreps, G. L., Croyle, R. T., Arora, N. K., Rimer, B. K., et al. (2005). Trust and sources of health information: the impact of the Internet and its implications for health care providers: findings from the first Health Information National Trends Survey. Archives of Internal Medicine, 165(22), 2618.

[16] Jacques Bughin, A. H. B., Michael Chui. (2011). How social technologies are extending the Organisation. Mcknsey Quarterly (November), 1-10.

[17] Karla Anderson, L. S., Garrett. D., (2012).Social media "likes" healthcare for marketing to social business: Health research Institute.

[18] Lanther, E. (2002). Psychology Research Methods. Retrieved 11/11/2013, from http://www.nvcc.edu/home/elanthier/methods/index. htm

[19] Murray, E., Lo, B., Pollack, L., Donelan, K., Catania, J., White, M., et al. (2003). The impact of health information on the internet on the physician-patient relationship: patient perceptions. Archives of Internal Medicine, 163(14), 1727.

[20] Ofcom. (2012). The Communications Market 2012: Ofcom.

[21] Office for National Statistics (2012), http://www.ons.gov.uk/ons/rel /rdit2/internet-access---households-and-individuals/2012/stb-internetaccess--households-and-individuals--2012.html

[22] Oppenheim, A. N. (2003). Questionnaire design, interviewing, and attitude measurement: Pinter Pub Ltd.

[23] Palmer, A., \& Koenig-Lewis, N. (2009).An experiential, social networkbased approach to direct marketing. Direct Marketing, 3(3), 162-176.

[24] Parker, R., \&Pettijohn, C. E. (2003). Ethical Considerations in the Use of Direct-To-Consumer Advertising and Pharmaceutical Promotions: The Impact on Pharmaceutical Sales and Physicians. Journal of Business Ethics, 48(3), 279-290.

[25] Powell, J., \& Clarke, A. (2002). The WWW of the World Wide Web: who, what, and why? Journal of Medical Internet Research, 4(1).

[26] Rice, R. E. (2006). Influences, usage, and outcomes of Internet health information searching: multivariate results from the Pew surveys. International Journal of Medical Informatics, 75(1).

[27] Ross, C., Orr, E. S., Sisic, M., Arseneault, J. M., Simmering, M. G., \& Orr, R. R. (2009). Personality and motivations associated with Facebook use. Computers in Human Behavior, 25(2), 578-586.

[28] Roxane Divol, D. E., Hugo Sarrazin (2012). Demystifying Social Media. [Marketing and Sales Practice]. McKinsey \&Company(April), 1-11.

[29] Saren, M. (2011).Marketing empowerment and exclusion in the information age.Marketing Intelligence \& Planning, 29(1), 39-48.
[30] Saunders, M. (2012). Doing Research in Business \& Management An Essential Guide to Planning Your Project: Prentice Hall.

[31] Scambler, A., Scambler, G., \& Craig, D. (1981).Kinship and friendship networks and women's demand for primary care.The Journal of the Royal College of General Practitioners, 31(233), 746.

[32] Sheth, J. N., \& Parvatiyar, A. (1995). Relationship marketing in consumer markets: antecedents and consequences. Journal of the Academy of marketing Science, 23(4).

[33] Sontag, S. (2001). Illness as metaphor and AIDS and its metaphors: Picador.

[34] Number of social media users worldwide 2010-2021[Internet]. [cited 2020 Mar 27]. Available from:Statista.www.statista.com>Internet>Social Media \&User-Generated Content

[35] Susannah Fox, M. D. (2013). Health Online Pew Internet \& American Life Project.

[36] Suziedelyte, A., (2012). How does searching for health information on the Internet affect individuals' demand for health care services?, Social Science \& Medicine, Vol 75, Issue 10, pp 1828-

[37] Taha, J., Sharit, J., \&Czaja, S. (2009). Use of and satisfaction with sources of health information among older Internet users and nonusers.The Gerontologist, 49(5), 663-673.

[38] Ventola, C. L. (2008). Challenges in evaluating and standardizing medical devices in health care facilities.Pharmacy and Therapeutics, 33(6), 348.

[39] Vermeire, E., Hearnshaw, H., Van Royen, P., \&Denekens, J. (2002). Patient adherence to treatment: three decades of research: A comprehensive review. Journal of clinical pharmacy and therapeutics, 26(5), 331-342.

[40] Xiao, N., Sharman, R., Rao, H.R., Upadhyaya, S., (2014), Factors influencing online health information search: An empirical analysis of a national cancer-related survey, Decision Support Systems, Vol 57, pp 417-427

[41] Ybarra, M., \& Suman, M. (2008). Reasons, assessments and actions taken: sex and age differences in uses of Internet health information. Health Education Research, 23(3).

[42] Zhao, Y., \& Zhang, J. (2017). Consumer health information seeking in social media: a literature review. Health information and libraries journal, 34(4), 268-283. https://doi.org/10.1111/hir.121921989.

[43] Zickuhr K, A. S. (2012). Digital differences: Pew Internet \& American Life Project. 